\title{
Multilevel Relationship Algorithm for Association Rule Mining used for Cooperative Learning
}

\author{
Deepak A Vidhate \\ Research Scholar
}

\author{
Parag Kulkarni, Ph.D \\ EKLaT Research, Pune
}

\begin{abstract}
Mining the Data is also known as Discovery of Knowledge in Databases. It is to get correlations, trends, patterns, anomalies from the databases which can help to build exact future decisions. However data mining is not the natural. No one can assure that the decision will lead to good quality results. It only helps experts to understand the data and show the way to good decisions.
\end{abstract}

Association Mining is the discovery of relations or correlations among an item set. An objective is to make rules from given multiple sources of customer database transaction. It needs increasingly deepening knowledge mining process for finding refined knowledge from data. Earlier work is on mining association rules at one level. Though mining association rules at various levels is necessary. Finding of interesting association relationship among large amount of data will helpful to decision building, marketing, \& business managing.

For generating frequent item set we are using Apriori Algorithm in multiple levels so called Multilevel Relationship algorithm (MRA). MRA works in first two stages. In third stage of MRA uses Bayesian probability to find out the dependency \& relationship among different shops, pattern of sales \& generates the rule for learning. This paper gives detail idea about concepts of association mining, mathematical model development for Multilevel Relationship algorithm and Implementation \& Result Analysis of MRA and performance comparison of MRA and Apriori algorithm.

\section{Keywords}

Apriori Algorithm, Association rule, Bayesian Probability, Data mining, Multilevel learning

\section{INTRODUCTION}

Machine Learning deals with the design of programs that can learn rules from data, adapt to changes, and improve performance with experience. In addition to being one of the initial thoughts of Computer Science, Machine Learning has become vital as computers are expected to solve increasingly complex problems and become more integrated into daily lives. These include identifying faces in images, autonomous driving in the desert, finding relevant documents in a database, finding patterns in large volumes of scientific data, and adjusting internal parameters of systems to optimize performance. Alternatively methods that take labeled training data and then learn appropriate rules from the data seem to be the best approach to solve the problems. Moreover, it needs a system that can adapt to varying conditions which is userfriendly by adapting to needs of their individual users, and also can improve performance over time[1].

Association rule mining concept has been applied to market domain and specific problem has been studied, the management of some aspects of a shopping mall, and an architecture that makes it possible to construct agents capable of adapting the association rules has been used.
A shopping mall is a cluster of independent shops, planned and developed by one or several entities, with a common objective. The size, commercial mixture, common services and complementary activities developed are all in keeping with their surroundings. A shopping mall needs to be managed and, the management includes solving incidents or problems in a dynamic environment[2].

As such, a shopping mall can be seen as a large dynamic problem, in which the management required depends on the variability of the products, clients, opinions. Aim is to develop an open system, capable of incorporating as many agents as necessary, agents that can provide useful services to the clients not only in this shopping centre, but also in any other environment such as the labor market, educational system, medical care, etc.

Data mining refers to extracting knowledge from large quantity of data. Interesting association can be discovered among a large set of data items by association rule mining. The finding of interesting relationship among large amount of business transaction records can help in many business decisions making process, such as catalog plan, cross marketing and loss leader analysis[3]. However, previous work has been focused on mining association rules at a single concept level. There are applications, which need to get associations at multiple concept levels.

Real world problem can be expressed in term of mathematical model and mathematical solutions can be found out. Following stages represents the process for solving the real world problems.

- Study of basic concepts for mathematical modeling

- Mathematical Modeling of the system (MRA)

- Implementation \& Result analysis of MRA

The focus was on working on mathematical model development for multilevel association rule mining. Multilevel Apriori algorithm and bayesian probability estimation is not combined in any of the previous work. It is the novel move towards the mining association rule. Efficiency of original Apriori algorithm has been increased due to multilevel architecture.

\section{ASSOCIATION RULE}

Mining association rule is finding the interesting association or correlation relationship among large set of data items. Many industries are becoming interested in mining association rule from their database as massive amount of data constantly being collected \& stored in database. Relationship among the business traction records can help to design catalog, loss leader analysis, cross marketing \& other business decision making process.

The discovery of such association can help retailers to develop marketing strategies by gaining insight into which items are frequently purchased together by customers. This information can increased sale by helping retailers to do selective marketing \& plan their shelf space. One of the 
motivating examples for association rule mining is marker basket analysis[4]

Market basket analysis is useful for retailers to plan which item to put on sale at reduced price. If customer tends to purchase shirt of Bombay ding and jeans of Levis together, then having a sale on jeans may encourage the sale of shirt as well as jeans. Buying patterns reflects which items are frequent associated or purchased together. These patterns are represented in the form of association rules. For example, customer who purchase shirt-Bombay ding also tends to buy jeans Levis at the same time is represented in association rule (2.1) below.

\section{Shirt-Bombay ding $\Rightarrow$ jeans-levis} [supp $=2 \%$, conf $=60 \%]$

Rule support \& confidence are two measure rules. They respectively reflect the usefulness and certainty of discovered rules. A support of $2 \%$ for association rule means that $2 \%$ of all transactions under analysis show that shirt-Bombay ding and jeans-levis are purchased together. A confidence of $60 \%$ means that $60 \%$ of customers who purchased shirt-Bombay ding also bought jeans Levis. Typically, association rule are considered interesting if they satisfy both a minimum support threshold and a minimum assurance threshold. Such threshold can be located by users or area expert.

Let $I=\left\{i 1, i 2, i 3 \ldots \ldots \ldots \ldots \ldots \ldots \ldots . . i_{d}\right\}$ set of all items in dataset

$$
\mathrm{T}=\left\{\mathrm{t} 1, \mathrm{t} 2, \mathrm{t} 3 \ldots \ldots \ldots \ldots \ldots \ldots \ldots \ldots . . . \mathrm{t}_{\mathrm{n}}\right\} \text { set of all transactions }
$$

Each transaction $t_{i}$ contains a subset of items chosen from I. A transaction $t_{j}$ is said to contain an itemset $X$ if $X$ is subset of $t_{j}$.

Association rule is an implication of the form of

$$
\mathrm{X} \Rightarrow \mathrm{Y} \text {, where } \mathrm{X} \subseteq \mathrm{I}, \mathrm{Y} \subseteq \mathrm{I} \& \mathrm{X} \cap \mathrm{Y}=\Phi
$$

The rule $\mathrm{X} \Rightarrow \mathrm{Y}$ holds in the transaction set $\mathrm{T}$ with support $\mathrm{s}$, where $s$ is percentage of transactions in $\mathrm{T}$ that contain $\mathrm{X} \mathrm{U} \mathrm{Y}$. The rule $\mathrm{X} \Rightarrow \mathrm{Y}$ has confidence $\mathrm{c}$ in the transaction set $\mathrm{T}$ if $\mathrm{c}$ is percentage in transactions in $\mathrm{T}$ containing $\mathrm{X}$ which also contain Y. i.e

Support $(\mathrm{X} \Rightarrow \mathrm{Y})=\mathrm{P}(\mathrm{X} \cup \mathrm{Y})$

Confidence $(\mathrm{X} \Rightarrow \mathrm{Y})=\mathrm{P}(\mathrm{Y} \mid \mathrm{X})$

Rules that satisfy both minimum support threshold (min_sup) and a minimum confidence threshold (min_conf) are called strong.

Itemset is nothing but set of items. If it contains $\mathrm{n}$ item is a n-itemset. The set \{shirt-Bombay ding, jeans-levis\} is 2 itemset. The occurrence of itemset is the number of transactions that contain the itemset. This is known as frequency or support count of the item set. It satisfies lowest amount of support if the occurrences frequency of itemset is greater than or equal to the product of min_sup \& total no of transactions in $\mathrm{T}$. If an itemset satisfy the minimum support then it is frequent itemset. Association mining has two steps process. In first step, find all frequent item sets. All of these item sets will arise at least as frequently as a pre-determined minimum support count. In second step, generate strong association rules from the frequent item sets and must satisfy lowest amount of support and minimum confidence. The overall performance of mining association rule is determined by the first step[5].

\subsection{Apriori Algorithm}

It employs an iterative approach known as a level-wise search, where $(\mathrm{k}-1)$ itemsets are used to explore $\mathrm{k}$ item sets. First, the set of frequent 1-itemsets is found by scanning the database to collect the count for each item \& collecting those items that satisfy minimum support. The outcome is denoted L1. Then L1 is used to find L2, which is then used to find L3, and so on, until no more frequent item sets can be got. Getting of each $\mathrm{L}_{\mathrm{k}}$ requires one full scan of $\mathrm{D}[6]$.

To improve the efficiency of the level-wise generation of frequent itemsets, one takes advantage of the Apriori property. All nonempty subsets of a frequent itemset must also be frequent. This property is based on the following observation. If an itemset $\mathrm{A}$ does not satisfy the minimum support threshold, min_sup, then A is not frequent; i.e. $\mathrm{P}$ (A) < min sup. If an item $\mathrm{B}$ is added to the itemset $\mathrm{A}$, then the resulting itemset $A \cup B$ cannot occur more frequently than $A$. Therefore $A \cup B$ is not frequent either, that is $P(A \cup B)<$ min_sup.

A two-step process is used to find $\mathrm{L}_{\mathrm{k}}$ from $\mathrm{L}_{\mathrm{k}-1}$, for $\mathrm{k} \geq 2$ :

\subsubsection{Join step:}

To find $\mathrm{L}_{\mathrm{k}}$, a set of candidate $\mathrm{k}$-itemsets is generated by joining $L_{k-1}$ with itself. Candidate set is denoted by $C_{k}$. Suppose $\mathrm{L} 1$ and $\mathrm{L} 2$ be item sets in $\mathrm{L}_{\mathrm{k}-1}$. The notation $\mathrm{Li}$ [j] refers to the $j^{\text {th }}$ item in $\mathrm{L}_{\mathrm{i}}$. Thus in $\mathrm{L} 1$, the last item and the next to the last item are given respectively by $\mathrm{L} 1_{[\mathrm{k}-1]}$ and $\mathrm{L}_{[\mathrm{k}-2]}$. Any two itemsets $\mathrm{L}_{\mathrm{k}-1}$ are joined if their first $(\mathrm{k}-2)$ items are in frequent. Then members L1 and L2 are joined if

$$
\begin{aligned}
& (\mathrm{L} 1[1]=\mathrm{L} 2[1]) \wedge(\mathrm{L} 1[2]=\mathrm{L} 2[2]) \wedge \ldots \wedge \\
& \left(\mathrm{L}_{[\mathrm{k}-2]}=\mathrm{L}_{[\mathrm{k}-2])} \wedge\left(\mathrm{L}_{[\mathrm{k}-1]}<\mathrm{L} 2_{[\mathrm{k}-1]}\right)\right.
\end{aligned}
$$

The condition $\mathrm{L} 1_{[\mathrm{k}-1]}<\mathrm{L} 2_{[\mathrm{k}-1]}$ ensures that no duplicates are created. The outcome of itemset formed by joining L1 and L2 is $\left\{\mathrm{L}_{[1]}, \mathrm{L} 1_{[2]} \ldots \ldots \ldots . . . \mathrm{L} 1_{[\mathrm{k}-2]}, \mathrm{L} 1_{[\mathrm{k}-1]}, \mathrm{L} 2_{[\mathrm{k}-1]}\right\}$

\subsubsection{Prune step:}

Set $C_{k}$ is a superset of $L_{k}$, because although all the frequent kitemsets are included in $\mathrm{C}_{\mathrm{k}}$, its members may or may not be frequent. One could scan the database to determine the count of each candidate in $\mathrm{C}_{\mathrm{k}}$ and eliminate any itemset that does not meet the minimum support threshold. This would then give $\mathrm{L}_{\mathrm{k}}$. However, $\mathrm{C}_{\mathrm{k}}$ can be huge, and so this could be very time-consuming.

To eliminate the infrequent itemsets, the Apriori property is used as follows. Any $(\mathrm{k}-1)$-itemset that is not frequent cannot be a subset of a frequent $\mathrm{k}$-itemset. Hence, if any $(\mathrm{k}-1)$ itemset of a candidate $\mathrm{k}$-itemset is not in $\mathrm{L}_{\mathrm{k}-1}$, then the candidate cannot be frequent either and so can be removed from $C_{k}$. This subset testing can be done quickly by maintaining a hash tree of all frequent itemsets. We illustrate the use of the Apriori algorithm for finding frequent itemsets in our transaction database, D[7].

Table 2.1: Transaction data set

\begin{tabular}{|c|c|}
\hline $\begin{array}{c}\text { Transaction } \\
\text { ID Items }\end{array}$ & $\begin{array}{c}\text { Transaction } \\
\text { ID Items }\end{array}$ \\
\hline T1 SH & A,SH \\
\hline T2 SH & B,TSH \\
\hline T3 SH & B, TSH \\
\hline
\end{tabular}




\begin{tabular}{|c|c|}
\hline T4 SH & A, SH \\
\hline T5 SH & A, TSH \\
\hline T6 SH & B,TSH \\
\hline T7 SH & A, TSH \\
\hline T8 SH & A, SH \\
\hline T9 SH & A, SH \\
\hline
\end{tabular}

In the first iteration of the algorithm, each item is a member of the set of candidate's 1-itemsets, C1. The algorithm simply scans all the transactions in order to count the number of occurrences of each item.

Table 2.2: Transaction 1-itemset $\mathrm{C} 1$ with count

\begin{tabular}{|c|c|}
\hline C1 Itemset & Support count \\
\hline SH-A & 06 \\
\hline SH-B & 07 \\
\hline TSH-P & 06 \\
\hline TSH-Q & 02 \\
\hline J-X & 02 \\
\hline J-Y & 01 \\
\hline
\end{tabular}

The set of frequent 1-itemsets, L1, consists of the candidate itemsets satisfying the minimum support count of 2 . Thus all the candidates in $\mathrm{C} 1$, except for $\{\mathrm{J}-\mathrm{Y}\}$, are in $\mathrm{L} 1$.

Table 2.3: Transaction 1-itemset L1 support 2

\begin{tabular}{|c|c|}
\hline L1 Itemset & Support count \\
\hline SH-A & 06 \\
\hline SH-B & 07 \\
\hline TSH-P & 06 \\
\hline TSH-Q & 02 \\
\hline J-X & 02 \\
\hline
\end{tabular}

To discover the set of frequent 2-itemsets, L2, the algorithm joins L1 with itself to generate a candidate set of 2-itemsets, $\mathrm{C} 2$. Note that no candidates are removed from $\mathrm{C} 2$ during the pruning step since each subset of the candidates is also frequent.

Table 2.4: Transaction 2-itemset C2

\begin{tabular}{|c|}
\hline C2 itemset \\
\hline (SH-A)-(SH-B) \\
\hline (SH-A)-(TSH-P) \\
\hline (SH-A)-(TSH-Q) \\
\hline (SH-A)-(J-X) \\
\hline (SH-B)-(TSH-P) \\
\hline (SH-B)-(TSH-Q) \\
\hline (SH-B)-(J-X) \\
\hline (TSH \\
\hline (TSH \\
\hline (TSH \\
\hline
\end{tabular}

\section{MULTILEVEL RELATIONSHIP ALGORITHM}

Multilevel Relationship algorithm works in three stages. In first two stages it utilizes apriori algorithm for finding out frequent itemsets. Third stage of MRA uses bayesian probability to find out the dependency \& relationship amongst different shops and generates the rules for learning.

Let the system $\mathrm{S}$ be represented as

$\mathrm{S}=\left\{\mathrm{I}, \mathrm{O}, \mathrm{f}_{\mathrm{s}} \mid \Phi_{\mathrm{s}}\right\}$
$\mathrm{I}=$ Input Datasets

$\mathrm{O}=$ Output Patterns

$\mathrm{O}=\mathrm{f}_{\mathrm{s}}(\mathrm{I}) \quad \forall \Phi_{\mathrm{s}}$

$\mathrm{f}_{\mathrm{s}}: \mathrm{I} \rightarrow \mathrm{O}$ be ONTO function

Objective was to find out pattern of sale from given dataset of three different shops for particular time period.

Input dataset $I=\{X, Y, Z\}$ such that $X=\{x 1, x 2, x 3\}$, $\mathrm{Y}=\{\mathrm{y} 1, \mathrm{y} 2, \mathrm{y} 3\}$ and $\mathrm{Z}=\{\mathrm{z} 1, \mathrm{z} 2, \mathrm{z} 3\}$

Success output $\mathrm{O}=\{\mathrm{P}(\mathrm{X} 0 \mid \mathrm{Y} 0), \quad \mathrm{P}(\mathrm{X} 0 \mid \mathrm{Z} 0), \mathrm{P}(\mathrm{X} 1 \mid \mathrm{Y} 1)$, $\mathrm{P}(\mathrm{Y} 1 \mid \mathrm{Z} 1) \ldots \ldots \ldots . . .$.

Multilevel Relationship Algorithm is applied on given input dataset i.e. $I=\{X, Y, Z\}$ where $X=\{x 1, x 2, x 3\}, Y=\{y 1, y 2, y 3\}$ and $\mathrm{Z}=\{\mathrm{z} 1, \mathrm{z} 2, \mathrm{z} 3\}$.

First stage gives Level 1 association amongst items in the same shop using knowledge base. It is called as local frequent itemsets generated in first phase. During second stage it uses individual knowledge base and level 1 association that was generated in stage I from same shops to find out the frequent item sets i.e. $\mathrm{x} 1(0), \mathrm{x} 2(3), \mathrm{x} 3(1) \ldots .$. .etc. It is called as global frequent itemsets.

\section{Stage 1:}

At first stage it found out Level 1 association amongst items in the same shop i.e. internal relationship between the same item types i. e. $x 1(0 \ldots \ldots . n), x 2(0 \ldots \ldots \ldots n), x 3(0 \ldots \ldots \ldots n)$ within the Cloth shop $(X)$ i.e. $O=f_{s}(X)$

Internal relationship between the same item types i. e. $\mathrm{y} 1(0 \ldots \ldots n), \mathrm{y} 2(0 \ldots \ldots \ldots \mathrm{n}), \mathrm{y} 3(0 \ldots \ldots . . \mathrm{n})$ within the Jewelry shop $(\mathrm{Y})$ i.e. $\mathrm{O}=\mathrm{f}_{\mathrm{s}}(\mathrm{Y})$

Internal relationship between the same item types i. e. $\mathrm{z} 1(0 \ldots \ldots n), \mathrm{z} 2(0 \ldots \ldots \ldots \mathrm{n}), \mathrm{z} 3(0 \ldots \ldots \ldots)$ within the Footwear shop $(Z)$ i.e. $O=f_{s}(Z)$

\section{Stage 2:}

During second stage it uses individual knowledge base and level 1 association is generated in stage 1 of same shop to find out the frequent item sets i.e. $\mathrm{x} 1(0), \mathrm{x} 2(3), \mathrm{x} 3(1) \ldots \ldots$.etc is called as global frequent itemsets.

It gives sets of frequent item sets for the Cloth shop for different items i.e. Fx as $\mathrm{O}=\mathrm{f}_{\mathrm{s}}(\mathrm{x} 1, \mathrm{x} 2, \mathrm{x} 3)$

It gives sets of frequent item sets for the Jewelry shop for different items i.e. Fy as $\mathrm{O}=\mathrm{f}_{\mathrm{s}}(\mathrm{y} 1, \mathrm{y} 2, \mathrm{y} 3)$

It gives with sets of frequent item sets for the Footwear shop for different items i.e. Fz as $\mathrm{O}=\mathrm{f}_{\mathrm{s}}(\mathrm{z} 1, \mathrm{z} 2, \mathrm{z} 3)$

\section{Stage 3:}

It is necessary to determine dynamic behavior of $F_{i}$ for particular season. External Dependencies amongst Items Xi Yi........ Xn Yn has been found with Bayesian probability. New patterns are generated by Bayesian probability through which learning rules are predicted \& interpreted.

\section{Working of Multilevel Relationship Algorithm}

Let the sale of Item $\boldsymbol{X}$ at Cloth shop affects sale of item $\boldsymbol{Y}$ at Jewelry shop and item $\boldsymbol{Z}$ at Footwear. 
1. Apriori association mining algorithm is applied on each item in cloth shops separately i.e. Jean(X0), Tshirt(X1), Shirt(X2) and so on from the given large item sets. It was applied at two levels / phases in the same shop.

2. After applying Apriori algorithm at first level for different support value it provide with the internal dependency amongst individual items \& generate the individual knowledge base i.e. x1(0) $\rightarrow$ x1(1), x2(0) $\rightarrow \mathrm{x} 2(1), \mathrm{x} 3(0) \rightarrow \mathrm{x} 3(1)$.......etc. It is called as local frequent itemsets generated in first phase.

3. At second level Apriori algorithm was applied on newly generated individual knowledge base to find out the frequent item sets i.e. $\mathrm{x} 1(0), \mathrm{x} 2(3), \mathrm{x} 3(1) \ldots \ldots$.etc. It is called as global frequent itemsets.

4. It provided with sets of frequent item sets for the Cloth shop for different items i.e. Fx.

5. Similarly the algorithm is applied on Jewelry $\operatorname{shop}(Y) \&$ Footwear $\operatorname{shop}(Z)$ to determine frequent itemset on different items.

6. First Level output of Apriori algorithm provided internal association amongst the items i. e. $y 1(0) \rightarrow$ $\mathrm{y} 1(1), \mathrm{y} 2(0) \rightarrow \mathrm{y} 2(1), \mathrm{y} 3(0) \rightarrow \mathrm{y} 3(1) \quad \& \quad \mathrm{z} 1(0) \rightarrow \mathrm{z} 1(1)$, $\mathrm{z} 2(0) \rightarrow \mathrm{z} 2(1), \quad \mathrm{z} 3(0) \rightarrow \mathrm{z} 3(1) \ldots . .$. etc for Jewelry \& Footwear shop respectively.

7. Second level input of Apriori algorithm provided from newly generated individual knowledge base, the frequent item sets i.e. $\mathrm{y} 1(0), \mathrm{y} 2(3), \mathrm{y} 3(1), \mathrm{z} 1(1), \mathrm{z} 2(5), \mathrm{z} 3(6) \ldots \ldots$

8. It gives with sets of frequent item sets for the Jewelry \& Footwear shop for different items i.e. Fy \& Fz.

9. The context is generated under uncertainty in the form of frequent item sets Fx, Fy \& Fz. System constraints applied here are sale of items in a day, week, month or any particular season. This context is refereed as $F_{i}$ which is not constant, i.e. it changed seasonably.

10. Hence it is necessary to determine dynamic behavior of $F_{i}$ for particular season.

11. External Dependencies amongst Items $\mathrm{Xi} \rightarrow \mathrm{Yi} \ldots \mathrm{Xn}$ $\rightarrow$ Yn is found with Bayesian probability.

12. New patterns are generated by Bayesian probability though which learning rules could be predicted \& interpreted.

\section{ARCHITECTURE OF MRA}

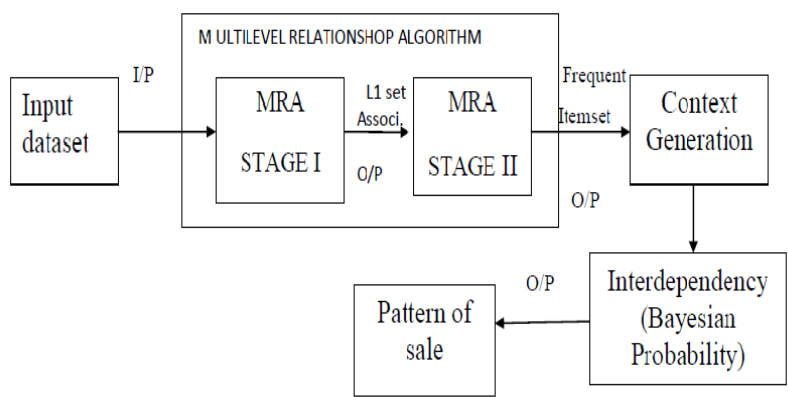

Figure 1 : MRA Architecture Diagram

Figure 1 shows the flow diagram which depicted the development of Multilevel Relationship Algorithm (MRA). Multilevel Relationship algorithm worked in three stages.

In first two stages it utilized association rule mining algorithm for finding out frequent itemsets. Datasets of three shops i.e. Cloth, Jewelry \& Footwear were given as an input to the stage I and Level 1 association between individual items had been found out. Level 1 association between individual items was given as an input to stage II and frequent itemsets had been found out. These frequent itemsets had generated new sale context. In stage III it used bayesian probability to find out the external dependency \& relationship amongst different shops, pattern of sale and generated the rules for cooperative learning. The algorithm consists of three sub modules:

MRA Stage I, MRA stage II, Interdependency Module

\section{MRA Stage I:}

At first stage it finds Level 1 association amongst items in the same shop i.e.

Internal relationship between the same item types i. e. $x 1(0 \ldots \ldots n), x 2(0 \ldots \ldots \ldots n), x 3(0 \ldots \ldots \ldots n)$ within the Cloth shop $(X)$ i.e.

$$
\begin{aligned}
& \mathrm{O}=\mathrm{f}_{\mathrm{s}}(\mathrm{X})=\mathrm{f}_{\text {stage_I_algorithm_apriori }}(\mathrm{X}) \\
& \therefore \mathrm{O}=\mathrm{f}_{\text {stage_I_algorithm_apriori }}\{\mathrm{x} 1(\ldots \mathrm{n})\}=\{\mathrm{x} 1(0) \rightarrow \mathrm{x} 1(1), \mathrm{x} 1(3) \\
& \rightarrow \mathrm{x} 1(2) \ldots\} \\
& \mathrm{O}=\mathrm{f}_{\text {stage_I_algorithm_apriori }}\{\mathrm{x} 2(0 \ldots \mathrm{n})\}=\{\mathrm{x} 2(2) \rightarrow \mathrm{x} 2(4), \mathrm{x} 2(2) \rightarrow \\
& \mathrm{x} 2(4) \ldots\} \\
& \mathrm{O}=\mathrm{f}_{\text {stage_I_algorithm_apriori }}\{\mathrm{x} 3(0 \ldots \mathrm{n})\}=\{\mathrm{x} 3(0) \rightarrow \mathrm{x} 3(3), \mathrm{x} 3(1) \rightarrow \\
& \mathrm{x} 3(5) \ldots\}
\end{aligned}
$$

Internal relationship between the same item types i. e. $\mathrm{Y} 1(0 \ldots \ldots \mathrm{N}), \mathrm{Y} 2(0 \ldots \ldots \ldots \mathrm{N}), \mathrm{Y} 3(0 \ldots \ldots . \mathrm{N})$ within the Jewellery shop (Y) i.e.

$$
\begin{aligned}
& \mathrm{O}=\mathrm{f}_{\mathrm{s}}(\mathrm{Y})=\mathrm{f}_{\text {stage_I_algorithm_apriori }}(\mathrm{Y}) \\
& \therefore \mathrm{O}=\mathrm{f}_{\text {stage_I_algorithm_apriori }}\{\mathrm{y} 1(0 \ldots \mathrm{n})\}=\{\mathrm{y} 1(1) \rightarrow \mathrm{y} 1(3), \mathrm{y} 1(2) \\
& \rightarrow \mathrm{y} 1(5) \ldots\} \\
& \mathrm{O}=\mathrm{f}_{\text {stage_I_algorithm_apriori }}\{\mathrm{y} 2(0 \ldots \mathrm{n})\}=\{\mathrm{y} 2(0) \rightarrow \mathrm{y} 2(1), \mathrm{y} 2(3) \rightarrow \\
& \mathrm{y} 2(7) \ldots\} \\
& \mathrm{O}=\mathrm{f}_{\text {stage_I_algorithm_apriori }}\{\mathrm{y} 3(0 . \mathrm{n})\}=\{\mathrm{y} 3(2) \rightarrow \mathrm{y} 3(3), \mathrm{y} 3(1) \rightarrow \\
& \mathrm{y} 3(4) \ldots \ldots\}
\end{aligned}
$$

Internal relationship between the same item types i. e. $\mathrm{z} 1(0 \ldots \ldots n), \mathrm{z} 2(0 \ldots \ldots \ldots \mathrm{n}), \mathrm{z} 3(0 \ldots \ldots \ldots \mathrm{n})$ within the Footwear shop $(Z)$

$$
\begin{aligned}
& \mathrm{O}=\mathrm{f}_{\mathrm{s}}(\mathrm{Z})=\mathrm{f}_{\text {stage_I_algorithm_apriori }}(\mathrm{Z}) \\
& \therefore \mathrm{O}=\mathrm{f}_{\text {stage_I_algorithm_apriori }}\{\mathrm{z} 1(0 \ldots . \mathrm{n})\}=\{\mathrm{z} 1(0) \rightarrow \mathrm{z} 1(2), \\
& \mathrm{z} 1(2) \rightarrow \mathrm{z} 1(4) \ldots\} \\
& \mathrm{O}=\mathrm{f}_{\text {stage_I_algorithm_apriori }}\{\mathrm{z} 2(0 \ldots \mathrm{n})\}=\{\mathrm{z} 2(1) \rightarrow \mathrm{z} 2(4), \mathrm{z} 2(1) \\
& \rightarrow \mathrm{z} 2(3) \ldots\} \\
& \mathrm{O}=\mathrm{f}_{\text {stage_I_algorithm_apriori }}\{\mathrm{z} 3(0 \ldots \mathrm{n})\}=\{\mathrm{z} 3(0) \rightarrow \mathrm{z} 3(3), \mathrm{z} 3(2) \\
& \rightarrow \mathrm{z} 3(5) \ldots\}
\end{aligned}
$$




\section{MRA Stage II:}

During second stage it uses individual knowledge base and level 1 association is generated in stage 1 of same shop to find out the frequent item sets i.e. $\mathrm{x} 1(0), \mathrm{x} 2(3), \mathrm{x} 3(1) \ldots \ldots$. etc is called as global frequent itemsets.

It gave sets of frequent item sets for the Cloth shop for different items i.e. Fx as below.

$\mathrm{O}=\mathrm{f}_{\mathrm{s}}(\mathrm{x} 1, \mathrm{x} 2, \mathrm{x} 3)$

$\mathrm{O}=\mathrm{f}_{\text {phase_II_algorithm_apriori }}\{\mathrm{x} 1, \mathrm{x} 2, \mathrm{x} 3\}=\{\mathrm{x} 1(0) \rightarrow \mathrm{x} 2(1), \mathrm{x} 2(3) \rightarrow$ $\mathrm{x} 3(2), \mathrm{x} 3(0) \rightarrow \mathrm{x} 2(2) \ldots\}$

It gives sets of frequent item sets for the Jewelry shop for different items i.e. Fy as below

$\mathrm{O}=\mathrm{f}_{\mathrm{s}}(\mathrm{y} 1, \mathrm{y} 2, \mathrm{y} 3)$

$\mathrm{O}=\mathrm{f}_{\text {phase_II_algorithm_apriori }}\{\mathrm{y} 1, \mathrm{y} 2, \mathrm{y} 3\}=\{\mathrm{y} 1(0) \rightarrow \mathrm{y} 2(1), \mathrm{y} 2(3) \rightarrow$ $\mathrm{y} 3(2), \mathrm{y} 3(0) \rightarrow \mathrm{y} 2(2) \ldots \ldots\}$

It gives with sets of frequent item sets for the Footwear shop for different items i.e. Fz as below

$\mathrm{O}=\mathrm{f}_{\mathrm{s}}(\mathrm{z} 1, \mathrm{z} 2, \mathrm{z} 3)$

$\mathrm{O}=\mathrm{f}_{\text {phase_II_algorithm_apriori }}\{\mathrm{z} 1, \mathrm{z} 2, \mathrm{z} 3\}=\{\mathrm{z} 1(0) \rightarrow \mathrm{z} 2(1), \mathrm{z} 2(3)$

$\rightarrow \mathrm{z} 3(2), \mathrm{z} 3(0) \rightarrow \mathrm{z} 2(2) \ldots\}$

\section{MRA Stage 3:}

\section{Interdependency by Bayesian Probability}

It is necessary to determine dynamic behavior of $\mathbf{F}_{\mathbf{i}}$ for particular season. External Dependencies amongst Items $\mathrm{Xi} \rightarrow \mathrm{Yi} \ldots . . \mathrm{Xn} \rightarrow \mathrm{Yn}$ is found with Bayesian probability. New patterns are generated by Bayesian probability through which learning rules are predicted \& interpreted. Dependency between itemsets of Cloth shop (Fx) and Jewelry shop (Fy) is find out as

$P(X \mid Y)=\frac{P(Y \mid X) P(X)}{P(Y)}$

$P(x 1, x 2, \ldots x n \mid y 1, y 2, . . y n)$

$=\frac{P(y 1, y 2 . . y n \mid x 1, x 2 \ldots x n) P(x 1, x 2 . . x n)}{P(y 1, y 2 \ldots y n)}$

Dependency between itemsets of Jewelry shop (Fy) and Footwear shop $(\mathrm{Fz})$ is find out as

$P(Y \mid Z)=\frac{P(Z \mid Y) P(Y)}{P(Z)}$

$P(y 1, y 2, \ldots y n \mid z 1, z 2, \ldots z n)$

$=\frac{P(z 1, z 2 . . z n \mid y 1, y 2 . . y n) P(y 1, y 2 . . y n)}{P(z 1, z 2 \ldots . z n)}$

Dependency between itemsets of Footwear shop (Fz) and Cloth shop (Fx) is find out as

$P(Z \mid X)=\frac{P(X \mid Z) P(Z)}{P(X)}$

$P(z 1, z 2, \ldots z n \mid x 1, x 2, \ldots x n)$

$=\frac{P(x 1, x 2 \ldots x n \mid z 1, z 2 \ldots z n) P(z 1, z 2 . . z n)}{P(x 1, x 2 \ldots x n)}$
Three cases are possible for the system to find out interdependencies and for the correct prediction of learning rules.

Case 1: Sale of items in Footwear shop (Z) depends on sale of items in Jewelry $\operatorname{shop}(\mathrm{Y})$ and it is in turn depends on sale of items in Cloth shop (X). That means, $\mathrm{X}$ is a cause of $\mathrm{Y}$ and $\mathrm{Y}$ is a cause of $\mathrm{Z}$. Result is an increase in sale of items in Cloth shop (X) causes increase in sale of items in Jewelry shop (Y) which in turn cause increase in sale of items in Footwear shop (Z) [11].

Case 2: Sale of items in Footwear shop (Z) \& Jewelry shop $(\mathrm{Y})$ depends on sale of items in Cloth shop (X). That means $\mathrm{X}$ is a cause of $\mathrm{Y}$ and $\mathrm{Z}$. Two child nodes are independent given the parent. $\mathrm{Y} \& \mathrm{Z}$ are independent given the parent node $\mathrm{X}$. Result is increase in sale of items in Cloth shop (X) cause increase in sale of items in both the shops i.e. Jewelry shop (Y) \& Footwear shop (Z) [11].

Case 3: Sale of items in Footwear shop (Z) depend on sale of items in Cloth shop (X) and Jewelry shop (Y). That means X $\& \mathrm{Y}$ are the causes of $\mathrm{Z}$. A node has two parents that are independent unless child is given i.e. an event may have independent causes. Result is increase in sale of items in Cloth shop (X) \& Jewelry shop (Y) cause increase in sale of items in the Footwear shop (Z) provided sale of items in Cloth shop \& Jewelry shop does not depend on each other [11]

\section{EXPERIMENTAL RESULTS}

The experimental results that have been obtained through implementing MRA and Apriori algorithm are presented in this section. Multilevel relationship algorithm applied for finding the frequent itemset and external dependency amongst them. It comes up with pattern which can be further useful for leaning in cooperative system. Performance of Apriori and MRA has compared for various factors i.e. strength, support and interdependency. Graphs show the result comparison between Apriori and MRA.

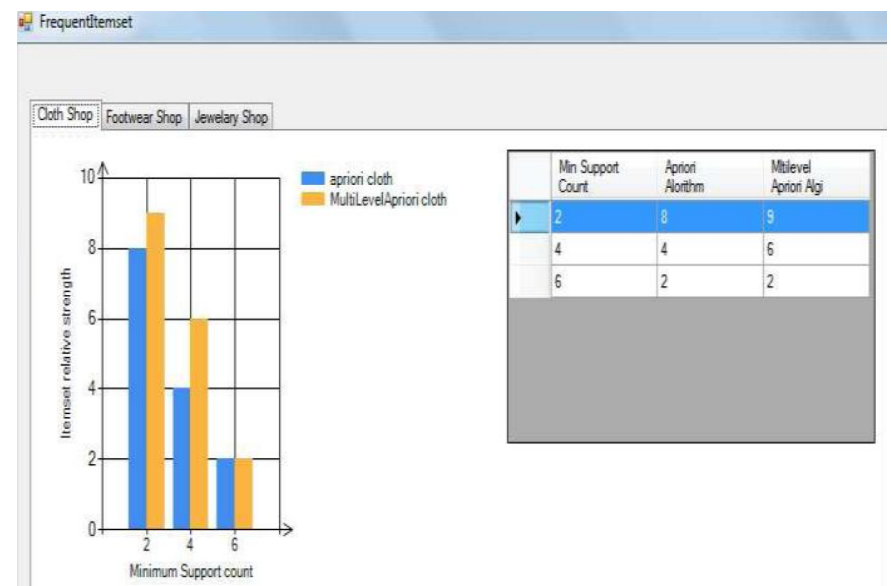

Figure 2: Comparison of Apriori \& MRA in terms of item strength with support for cloth shop 


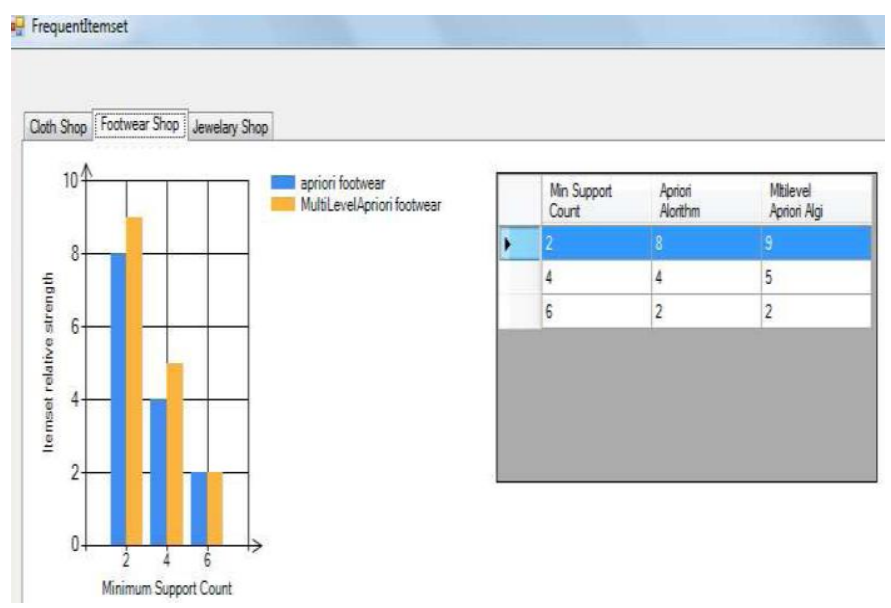

Figure 3: Comparison of Apriori \& MRA in terms of item strength with support for footwear shop

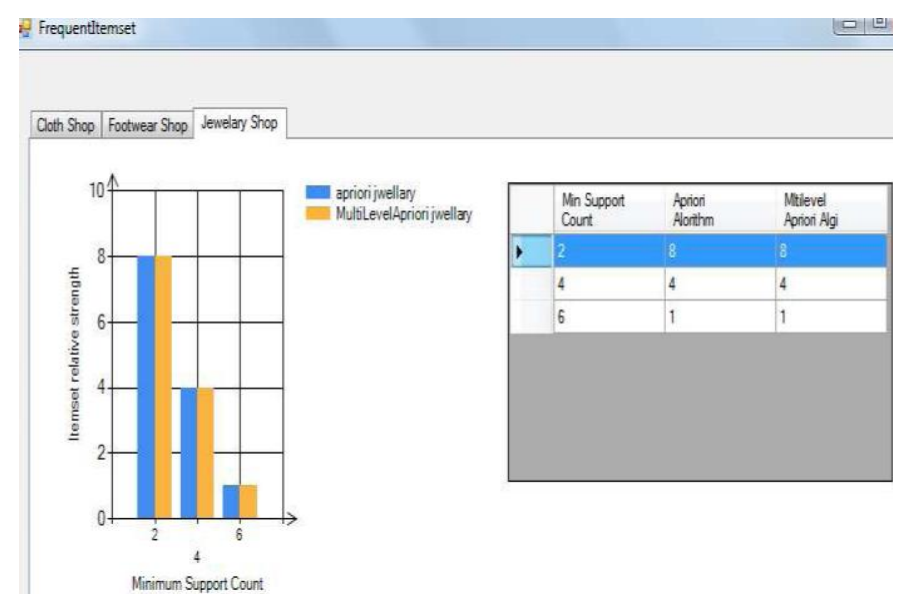

Figure 4: Comparison of Apriori \& MRA in terms of item strength with support for jewellery shop

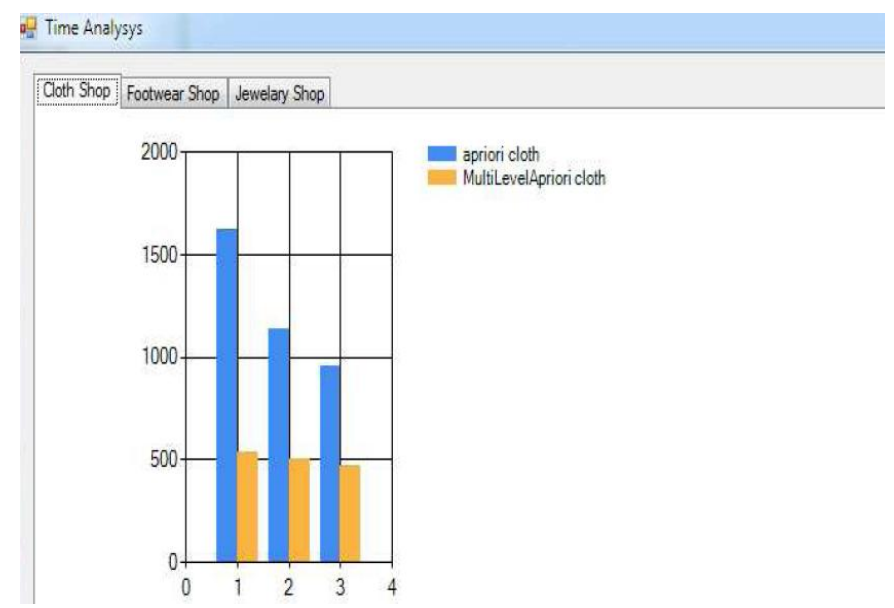

Figure 5: Comparison of Apriori \& MRA in terms of time (ms) \& support for cloth shop

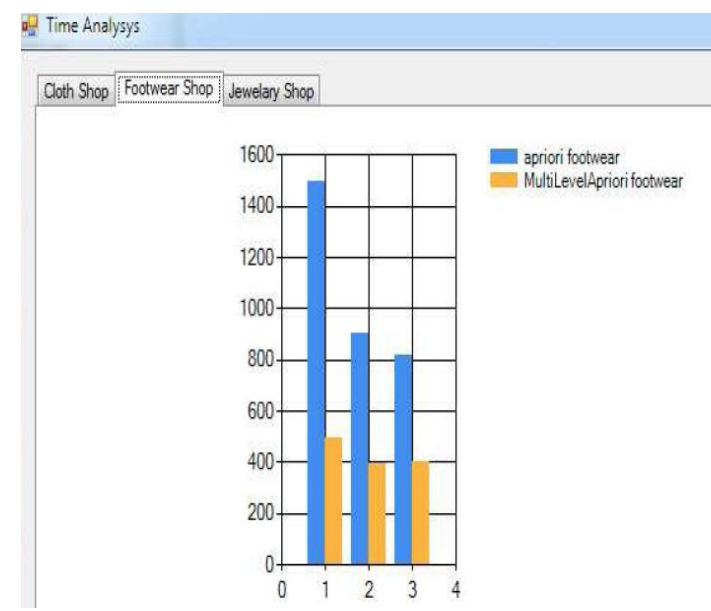

Figure 6: Comparison of Apriori \& MRA in terms of time (ms) \& support for footwear shop

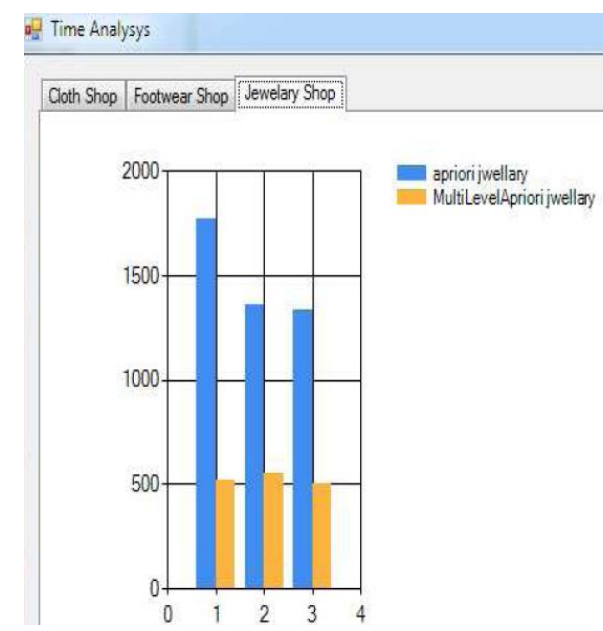

Figure 7: Comparison of Apriori \& MRA in terms of time (ms) \& support for jewellery shop

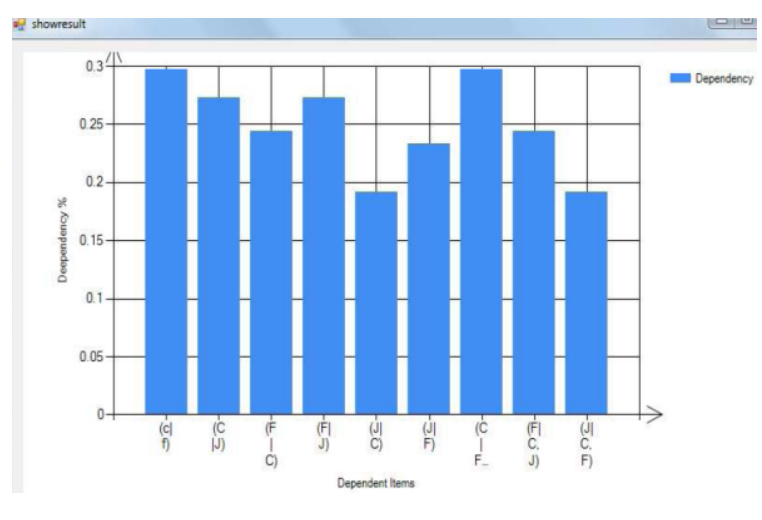

Figure 8: Percentage Interdependency among the three shops 
Simple Apriori algorithm shows only the frequent itemsets in each shop independently. It does not provide the internal dependency amongst individual items and cannot find out local frequent itemsets. Due to this, external dependencies are not found out between different shops and become unable to find out the learning rules and pattern of sale. Hence, there is need to develop modified approach which would enable to give internal \& external dependencies along with the learning rules. Multilevel Apriori algorithm and bayesian probability estimation gives the expected results.

\section{CONCLUSION}

The classical apriori algorithm widely used for association rule mining, this having important factors i.e. prediction rate and runtime. This system increase the efficiency of generating association rules based on these analysis and research. The new algorithm Multilevel Relationship Algorithm is better than the apriori algorithm. Through this algorithm is good to find the frequent item sets with minimum support. New pattern are generated by Bayesian probability though which learning rules are predicted and interpreted. Multilevel Apriori algorithm and Bayesian probability estimation is not combined in any of the previous work. This is novel move towards the mining association rule. Efficiency of original algorithm has been increased due to multilevel architecture. Two passes of algorithm has been performed for more accuracy and efficiency. This multilevel approach is especially beneficial when efficiency required is important such as in computationally intensive applications that must be run frequently. This is new approach applied to the set of data from different shops for finding frequent item sets and finding external dependencies amongst them. It comes up with patters which can be further useful for learning in cooperative algorithms.

\section{REFERENCES}

[1] R. Agrawal, T. Imielinski, and A. Swami "Mining associations between sets of items in massive databases" In Proc. of the ACM SIGMOD Int'l Conference on Management of Data, 1993.

[2] R. Agrawal and R. Srikant "Fast algorithms for mining association rules in large databases" In Proceedings of the Twentieth International Conference on Very Large Databases, pages 487-499, Santiago, Chile, 1994.

[3] Mining Frequent Patterns without Candidate Generation - Jiawei Han, Jian Pei, Yiwen Yin

[4] Rakesh Agrawal, Christos Faloutsos, \& Arun Swami "Efficient similarity search in sequence databases" In Proc. of the Fourth International Conference on Foundations of Data Organization and Algorithms, Chicago, October 1993. Also in Lecture Notes in Computer Science 730, Springer Verlag, 1993, 69-84.

[5] Rakesh Agrawal, SaktiGhosh, Tomasz Imielinski, BalaIyer, and Arun Swami "An interval classifer for database mining applications" Proc. of the VLDB Conference, pages 560-573, Vancouver, British Columbia, Canada, August 1992.

[6] Rakesh Agrawal, Tomasz Imielinski and Arun Swami "Database mining: A performance perspective" published in IEEE Transactions on Knowledge and Data Engineering, 5(6):914 925, December 1993. Special Issue on Learning and Discovery in Knowledge-Based Databases.
[7] Aaron Ceglar \& John F. Roddick "Association Mining” in ACM Computing Surveys, Vol. 38, No. 2, Article 5, Publication date: July 2006.

[8] Baoqing Jiang,WeiWang and Yang $\mathrm{Xu}$ "The Math Background of Apriori Algorithm"

[9] Jiawei Han \& Micheline Kamber "Data Mining: Concepts \& Techniques" Second Edition, Elsevier publication.

[10] Pang-Ning Tan, Vipin Kumar \& Michael Steinbach "Introduction to Data Mining" by Pearson Education Inc.

[11] Ethem Alpaydin "Introduction to Machine Learning" Second Edition, MIT Press by PHI.

[12] Tom Mitchell "Machine Learning" McGraw Hill International Edition.

[13] Kishor S. Trivedi "Probability \& Statistics with Reliability, Queuing and Computer Science Applications" by PHI.

[14] Liviu Panait Sean Luke "Cooperative Multi-Agent Learning: The State of the Art", published in Journal of Autonomous Agents and Multi-Agent Systems Volume 11 Issue 3, pp. 387 - 434, 2005

[15] Young-Cheol Choi, Student Member, Hyo-Sung Ahn "A Survey on Multi-Agent Reinforcement Learning: Coordination Problems", IEEE/ASME International Conference on Mechatronics and Embedded Systems and Applications, pp. $81-86,2010$.

[16] Zahra Abbasi, Mohammad Ali Abbasi "Reinforcement Distribution in a Team of Cooperative Q-learning Agent", Proceedings of the $9^{\text {th }}$ ACIS International Conference on Software Engineering, Artificial Intelligence, Networking, and Parallel/Distributed Computing, IEEE Computer Society, pp. 154-160, 2008.

[17] Babak Nadjar Araabi, Sahar Mastoureshgh, \& Majid Nili Ahmadabadi "A Study on Expertise of Agents and Its Effects on Cooperative $Q$-Learning" ,IEEE Transactions on Evolutionary Computation, vol:14, pp:23-57, 2010.

[18] Jun-Yuan Tao, De-Sheng Li "Cooperative Strategy Learning In Multi-Agent Environment With Continuous State Space", IEEE International Conference on Machine Learning and Cybernetics, pp.2107 - 2111, 2006.

[19] Dr. Hamid R. Berenji David Vengerov "Learning, Cooperation, and Coordination in Multi-Agent Systems", in Proceedings of $9^{\text {th }}$ IEEE International Conference on Fuzzy Systems, 2000.

[20] M.V. Nagendra Prasad \& Victor R. Lesser "Learning Situation-Specific Coordination in Cooperative Multiagent Systems" in Journal of Autonomous Agents and Multi-Agent Systems, Volume 2 Issue 2, pp. 173 - 207, 1999.

[21] Edmund H Durfee, Victor R Lesser and Daniel D Corkill "Trends in Cooperative Distributed Problem Solving", IEEE Transactions on Knowledge and Data Engineering, 1995.

[22] Sandip Sen \& Mahendra Sekaran "Individual learning of coordination knowledge", in Journal of Experimental \& Theoretical Artificial Intelligence, vol.10 issue3, pp. 333-356, 1998 
[23] Ronen Brafman \& Moshe Tennenholtz "Learning to Coordinate Efficiently: A Model-based Approach", in Journal of Artificial Intelligence Research, Volume 19 Issue 1, pp. 11-23, 2003.

[24] Michael Kinney \& Costas Tsatsoulis "Learning Communication Strategies in Multiagent Systems", in Journal of Applied Intelligence, Volume 9 Issue 1, pp 7191, 1998.

[25] Georgios Chalkiadakis \& Craig Boutilier "Coordination in Multiagent Reinforcement Learning: A Bayesian Approach" in AAMAS '03 Proceedings of the $2^{\text {nd }}$ International Joint Conference on Autonomous agents and multiagent systems, pp. 709-716, 2003.

[26] Chern Han Yong \& Risto Miikkulainen "Coevolution of Role-Based Cooperation in Multi-Agent Systems", in technical Report AI07-338, University of Texas at Austin, 2007.

[27] Hung H Bui Svetha Venkatesh and Dorota Kieronska "A Framework for Coordination and Learning among Team of Agents", in Agents and Multi-Agent Systems: Formalisms, Methodologies and Applications, Lecture Notes in Artificial Intelligence, Volume 1441, 1997.

[28] Jun Huang, N. R. Jennings \& John Fox "An Agent Architecture for Distributed Medical Care" in Lecture Notes in Computer Science, Volume 890/1995, pp. 219232, 1995.
[29] Thomas Haynes \& Sandip Sen "Adaptation Using Cases in Cooperative Groups", in workshop proceedings of Association for the Advancement of Artificial Intelligence (AAAI), 1996.

[30] Richardson Ribeiro, André P. Borges and Fabrício Enembreck "Interaction Models for Multiagent Reinforcement Learning", in the CIMCA '08 Proceedings of IEEE International Conference on Computational Intelligence for Modeling Control \& Automation, pp. 464-469, 2008.

[31] Herman Bruyninckx "Bayesian probability" ,Dept. of Mechanical Engineering, K.U. Leuven, Belgium, November 2002

[32] Chris Westbury "Bayes' For Beginners" Department of Psychology, P220 Biological Sciences Bldg., University of Alberta, Edmonton, AB, T6G 2E9, Canada.

[33] Bruno A. Olshausen "Bayesian probability theory" March 1, 2004

[34] Toshiharu Sugawara \& Victor Lesser "Learning to improve coordinated actions in cooperative distributed problem solving environments", in Journal of Machine Learning, Volume 33 Issue 2-3, pp.129-153, 1998.

[35] Hamid Berenji \& David Vengerov "Advantages of Cooperation between Reinforcement Learning Agents in difficult stochastic problems" in the $9^{\text {th }}$ IEEE International Conference on Fuzzy Systems, vol.2, pp. $871-876,2000$ 